\title{
Commentary
}

\section{Comments on the paper "Helping reviewers ask the right questions: The InfoQ framework for reviewing applied research" by Ron S. Kenett and Galit Shmueli ${ }^{1}$}

\author{
Asta Manninen \\ Member of the SJIAOS Editorial Board and member of the ESAC, European Statistical Advisory Committee \\ E-mail: asta.manninen@pp.inet.fi
}

The Editor-in-Chief of the Statistical Journal of the IAOS (SJIAOS), Prof. Fritz Scheuren has paid a lot of attention to the improvement of the entire publication process of the journal including the reviewing of papers and related quality issues. The paper by Ron $\mathrm{S}$. Kenett and Galit Shmueli [1] makes an important contribution to the efforts striving at high-quality papers and at an as effective review process as possible. The paper is comprehensive in reviewing current guidelines in applied journals and profound in presenting the concept and framework of Information Quality (InfoQ). Helping reviewers ask the right questions is much appreciated and so is the goal of expediting the reviewing cycle. The readership of the journal welcomes new knowledge timely delivered.

The quality of the papers is always at the core of the journal and the reviewers play a key role in supporting the authors to submit papers fulfilling the expected quality standard. Ron S. Kenett and Galit Shmueli propose a structured approach to the review process. They suggest an Information Quality (InfoQ) framework and a few guidelines to assist the reviewers, associate editors and editors in evaluating the submitted papers. Ron S. Kenett and Galit Shmueli also underline that utilising structured guidelines in the review work will ensure some homogeneity in the quality of the review process.

\footnotetext{
${ }^{1}$ R.S. Kenett and G. Shmueli, Helping authors and reviewers ask the right questions: The InfoQ framework for reviewing applied research, Statistical Journal of the IAOS, 32 (2016) 11-19.
}

Next I will provide a few comments on the Information Quality (InfoQ) framework and in doing so I will bear the mission and aims of the Statistical Journal of the International Association of Official Statistics (SJIAOS) in mind. In order to help the reviewers properly Ron S. Kenett and Galit Shmueli set out the context, i.e. the papers object to evaluation should involve data analysis and applied research. This is an important point of depature. The authors explain that the InfoQ framework ties the the goal, data, analysis and utility of an empirical study. Reviewers interested in applying the InfoQ framework in their work need an operationalisation, which is presented in Section 3 of the article "InfoQ Guidelines for Reviewers" [1]. The operationalisation defines the process of measuring the level of information quality to be composed of eight InfoQ dimensions and each of them accompanied by a few guiding questions to figure out the strength of the dimension.

Looking at the eight dimensions and related guiding questions one by one my comments are as follows:

- Data Resolution. This dimension is well known to reviewers of SJIAOS articles. Currently, this dimension is getting special attention as official statistics also utilise new types of data sources such as Big Data.

- Data structure. This dimension is also well known to reviewers of SJIAOS articles. This dimension is getting special attention partially for the same reason as the dimension Data Resolution, i.e. challenges caused by use of new types of data sources. 
- Data Integration. Reviewers of SJIAOS articles are aware of this dimension. The guiding questions raised by Ron S. Kenett and Galit Shmueli are very useful. Actually, the questions very much relate to the challenges currently facing official statistics on national and international level [2]3]. It is also worth observing that the SJIAOS has devoted a lot of attention and efforts to fostering consistency and coherence across statistical domains. This is about data interoperability and integration.

- Temporal Relevance. This dimension is very well known to reviewers of SJIAOS articles.

- Chronology of Data and Goal. Reviewers of SJIAOS articles are aware of this dimension. However, the dimension is challenging and requests special attention of the reviewers.

- Generalizability. This is a principal dimension well presented by Ron S. Kenett and Galit Shmueli. The guiding questions for the reviewers are most valuable; the fourth question are close to the challenge of open research.

- Operationalization. The dimension is of major importance taking into account the wide readership of the SJIAOS.

- Communication. This dimension is crucial for the SJIAOS and need all attention and support.

All in all, the InfoQ framework provides a systematic approach for the reviewing process of papers involving data analysis and applied research. The eight dimensions of the InfoQ are highly relevant. In addition the InfoQ could have paid more attention to novelty and to how well or comprehensively the paper is based on prior work, scientific and applied.

However, I envisage that reviewers of SJIAOS articles have to emphasize a number of additional questions and characteristics not fully featured in the presented InfoQ [1]. These questions derive from the aims and broad scope of the SJIAOS [4]. SJIAOS papers dealing with current and emerging issues of today's world and society necessarily face the challenge of international comparability of data and statistics. Papers dealing with new directions for official statistics, organisation of statistical services, innovative statistical products and services, or developing statistics to capture new phenomena, represent a few more examples requesting adequat questions to be asked by the reviewer. Papers contributing new insights about present and future trends falls within the guidelines of the SJIAOS. The assessment of these papers would need support not yet covered by InfoQ.

Ron S. Kenett and Galit Shmueli suggest in their final fourth section "Discussion" that journals such as the SJIAOS would adopt the InfoQ structured framework either formally or informally. I consider the suggestion for further discussion. In addition, I support the idea of bringing the InfoQ to knowledge of reviewers of SJIAOS papers. There are benefits to achieve from a framework and a checklist amended to cover the scope and content of SJIAOS papers meeting the aims of the SJIAOS. I would also like to add the fact that many of the articles published in the SJIAOS are based in papers presented and discussed at international conferences, and thus these papers have undergone quality assessment to some extent already before submission of the paper.

Reviewers do invaluable work on voluntary basis, often under work and time pressure. They share their profound knowledge and expertise to help the authors of papers, to secure the quality of the journal, and for the best of the international statistical society. Sincere thanks go to them.

\section{References}

[1] R.S. Kenett and G. Shmueli, Helping Reviewers Ask the Right Questions: The InfoQ Framework for Reviewing Applied Research. Statistical Journal of the IAOS 32 (2016), 11-19.

[2] C. Reimsbach-Kounatze, The Proliferation of "Big Data" and Implications for Official statistics and Statistical Agencies. A Preliminary Analysis. OECD Digital Economy Papers. 12 January 2015. http://www.oecd-ilibrary.org/science-and-technolo gy/the-proliferation-of-big-data-and-implications-for-officialstatistics-and-statistical-agencies_5js7t9wqzvg8-en.

[3] The ESS Vision 2020. European Statistical System Committee. Luxembourg, 14-15 May 2014. http://ec.europa.eu/eurostat/ documents/10186/756730/ESS-Vision-2020.pdf/8d97506bb802-439e-9ea4-303e905f4255.

[4] Statistical Journal of the IAOS, Aims \& Scope, http://www. iospress.nl/journal/statistical-journal-of-the-iaos/. 